\title{
Polymer Nanoparticle Engineering for Podocyte Repair: From in Vitro Models to New Nanotherapeutics in Kidney Diseases
}

Claudio Colombo, ${ }^{\S, \perp}$ Min Li, ${ }^{\dagger, *}$ Shojiro Watanabe, ${ }^{\ddagger}, \#$ Piergiorgio Messa, ${ }^{\neq}$Alberto Edefonti," Giovanni Montini, ${ }^{\|}$Davide Moscatelli, ${ }^{\S} \odot$ Maria Pia Rastaldi, ${ }^{, *}$ and Francesco Cellesi ${ }^{*, t,+, \$ \odot}$

${ }^{\dagger}$ Fondazione CEN - European Centre for Nanomedicine, Piazza Leonardo da Vinci 32, 20133 Milan, Italy

${ }^{\ddagger}$ Renal Research Laboratory, Fondazione IRCCS Ca’ Granda Ospedale Maggiore Policlinico, Via Pace 9, 20122 Milan, Italy

${ }^{\S}$ Dipartimento di Chimica, Materiali ed Ingegneria Chimica “G. Natta”. Politecnico di Milano, Via Mancinelli 7, 20131 Milan, Italy

"Pediatric Nephrology and Dialysis Unit, Department of Clinical Sciences and Community Health, University of Milan, Fondazione IRCCS Ca' Granda - Ospedale Maggiore Policlinico, Via Commenda, 20122 Milano, Italy

\section{Supporting Information}

ABSTRACT: Specific therapeutic targeting of kidney podocytes, the highly differentiated ramified glomerular cells involved in the onset and/or progression of proteinuric diseases, could become the optimal strategy for preventing chronic kidney disease. With this aim, we developed a library of engineered polymeric nanoparticles (NPs) of tuneable size and surface properties and evaluated their interaction with podocytes. NP cytotoxicity, uptake, and cytoskeletal effects on podocytes were first assessed. On the basis of these data, nanodelivery of dexamethasone loaded into selected biocompatible NPs was successful in repairing damaged podocytes. Finally, a three-dimensional in vitro system of co-culture of endothelial cells and podocytes was exploited as a new tool for mimicking the mechanisms of NP interaction with glomerular cells and the repair of the kidney filtration barrier.

\section{INTRODUCTION}

The study of the interaction of kidneys with nanoparticles (NPs) is becoming an important area of research in nanomedicine, ${ }^{1}$ particularly in the field of nanotoxicology and theragnostics. $^{2-5}$

In the renal glomerulus, the ramified cells covering the external side of the glomerular basement membrane, that is, the podocytes, are the main gatekeeper of protein filtration. When podocytes work less efficiently due to stress or damage, proteinuria, the loss of proteins in the urine, and glomerular dysfunction inevitably take place. If not promptly treated, these conditions lead to progression of glomerular damage and renal failure. $^{6}$

Several experimental results have suggested that most drugs currently in use to treat or slow progression of glomerular damage, such as steroids, immunosuppressive agents, and ACEinhibitors, have a direct action on podocytes. ${ }^{7-9}$

These therapies are charged by severe side effects, particularly when a systemic prolonged administration is required. Therefore, the future development of a specific podocyte-targeted nanodelivery system may represent a major breakthrough in kidney disease research because it would minimize dose and adverse drug reactions in current therapies and promote the safe utilization of novel drugs directed against specific molecular pathways activated during cell damage. In addition, a deeper understanding of the mechanisms of the interaction between podocytes and engineered NPs could be beneficial for developing new diagnostics of podocyteassociated diseases. ${ }^{1}$

Although renal clearance and accumulation of NPs have been the focus of recent studies, ${ }^{2,3}$ precise characterization of the interaction between different nanomaterials and glomerular cells is still lacking. In the context of nanotoxicology, recent reports have shown that administration of inorganic NPs (such as nanosized silver and copper) to healthy rodents stimulated morphological changes of primary and second podocyte ramifications ${ }^{10}$ and induced apoptosis through oxidative stress in vitro. ${ }^{11,12}$ On the other hand, in vivo evidence of inorganic (iron oxide, ${ }^{13}$ gold $^{14}$ ) NP uptake by podocytes without affecting kidney function was also reported. Quantum dots functionalized with cyclo(RGD) peptide promoted selective binding of $\alpha \nu \beta 3$ integrin receptor on podocytes, followed by internalization in vitro, in view of a possible application as targeted therapy and diagnostics. ${ }^{1}$

The goal of this work was to develop in vitro models to evaluate the interaction of engineered polymeric NPs with

Received: November 24, 2016

Accepted: February 8, 2017

Published: February 20, 2017 
A

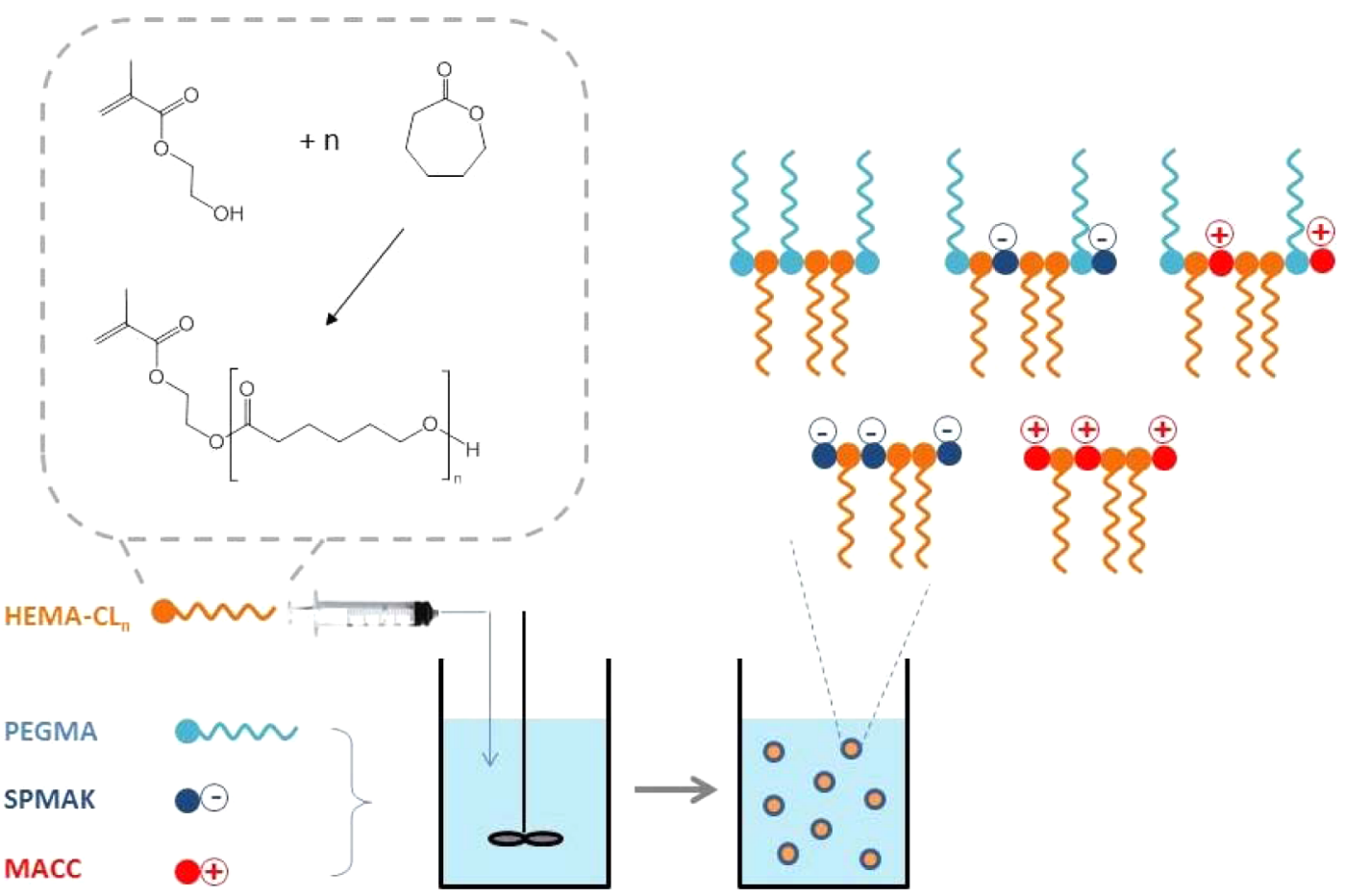

MSSEP/BEP

B

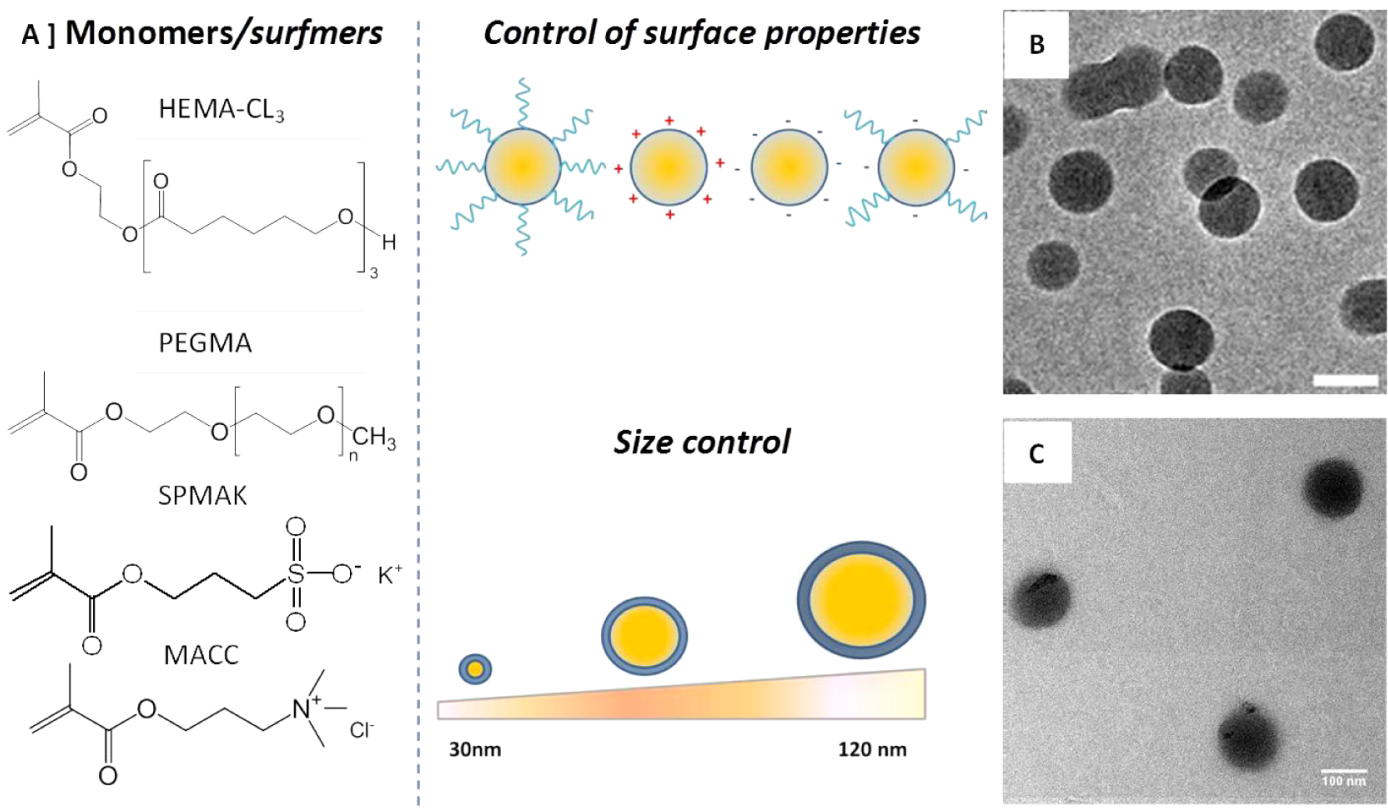

Figure 1. (A) Sketch of the BEP and MSSEP methods used for the synthesis of polymeric NPs. (B) Chemical structure of the monomers/surfmers used for the synthesis of NPs with different sizes and surface properties (a). Transmission electron microscopy (TEM) images of NP9 (b) and NP10 (c) (scale bar $100 \mathrm{~nm}$ ).

podocytes, aiming to (a) unveil fundamental mechanisms of podocyte response to colloidal nanomaterials, depending on the physicochemical characteristics of the NPs, and (b) design new nanocarriers for potential targeted drug delivery to podocytes in proteinuric diseases.

To fulfill our goals, a library of colloidal nanomaterials of defined size and surface chemistry was prepared. Poly $(\varepsilon-$ caprolactone)-based NPs of a narrow size distribution and tunable size in the $30-120 \mathrm{~nm}$ range were synthesized according to emulsion free radical polymerization techniques. ${ }^{15-17}$ Bulk ring-opening polymerization of $\varepsilon$-caprolactone with 2-hydroxyethyl methacrylate (HEMA) as an initiator was first carried out to produce biodegradable polyester-based methacrylates, which were used as macromonomers in starved 
semibatch emulsion polymerization (MSSEP) and batch emulsion polymerization (BEP). ${ }^{15}$ With the optimal use of polymerizable methacryloyl surfactants (i.e., positively, negatively charged, PEGylated surfmers), the surface chemistry of the NPs was also controlled (Figure 1).

In vitro assessment of the effects of nanomaterials on podocytes was carried out by testing NP cytotoxicity and uptake, and cytoskeleton stress.

Possible podocyte repair by controlled drug nanodelivery was then analyzed. Finally, we took advantage of a recently developed $3 \mathrm{D}$ in vitro system based on a co-culture of endothelial cells and podocytes, ${ }^{18,19}$ in mimicking the mechanisms of NP interaction with glomerular cells and the repair of the filtration barrier.

\section{RESULTS AND DISCUSSION}

Library of Engineered Polymeric NPs. First, polyesterbased NPs were synthesized with controlled particle size and surface properties, using emulsion free radical polymerization techniques (Figure 1). Custom-made $\operatorname{poly}(\varepsilon$-caprolactone)based macromonomer (HEMA-CL $\mathrm{C}_{3}$ ) was co-polymerized with suitable surfmers, namely, poly(ethylene glycol) methacrylate (PEGMA), 3-sulfopropyl methacrylate potassium salt (SPMAK), and methacrylate choline chloride (MACC), to obtain neutral, negatively charged, and positively charged NPs, respectively (Figure 1).

The HEMA-CL $\mathrm{C}_{3}$ macromonomer was obtained through a bulk ring-opening polymerization of $\varepsilon$-caprolactone, using HEMA as the initiator, according to a recently developed procedure. $^{15}$

This hydrolyzable oligoester composed of three units of CL was selected as the macromonomer because of its capability to generate NPs with excellent biocompatibility, absence of toxicity in vitro and in vivo, ${ }^{17,20}$ and a relatively fast degradation kinetics. $^{21-24}$

BEP was adopted as the standard polymerization procedure, whereas MSSEP, in which the HEMA-CL ${ }_{3}$ macromonomer was slowly fed into the reactor, was used to obtain smaller NPs (Figure 1A). By changing the surfmer type and its weight ratio to the HEMA- $\mathrm{CL}_{3}$ macromonomer, NP latexes were produced with controlled size and surface charge. The average size, polydispersity index (PDI), and Z-potential of the produced NPs were evaluated via dynamic light scattering (DLS) measurements and are reported in Table 1 . Size distributions are shown in Figure 2.

The synthesis conditions were chosen with the aim of obtaining nearly monodisperse NPs with different sizes for each type of surface charge: a small average size between 30 and 40 $\mathrm{nm}$, a medium one comprised between 60 and $70 \mathrm{~nm}$, and a larger one between 110 and $120 \mathrm{~nm}$ (Figure 2) to test whether the particle size may influence the podocyte behavior in vitro.

Low hydrodynamic diameters were obtained by increasing the amount of surfmer and using MSSEP. ${ }^{25}$ Small PEGylated NPs (sample NP2, $40 \mathrm{~nm}$ ) were obtained by using PEGMA together with SDS as the surfactant because it was not possible to obtain such a small average size with only a PEGylated surfmer (Table 1). As expected, the PEGylated NPs produced with only PEGMA showed a slightly negative Z-potential due to the presence of sulfate groups from the free radical initiator KPS, which are covalently attached to the polymers. ${ }^{26}$ Alternatively, by mixing PEGMA with either SPMAK or MACC, weakly charged PEGylated NPs were also obtained (NP1, negatively charged, $37 \mathrm{~nm}$, and NP11, positively charged,
Table 1. NP Name, Emulsion Polymerization Conditions, and Final Physicochemical Characteristics Obtained by DLS

\begin{tabular}{|c|c|c|c|c|c|c|}
\hline name & $\begin{array}{l}\text { surface } \\
\text { charge }\end{array}$ & $\begin{array}{l}\text { surfmer content } \\
(\% \mathrm{w} / \mathrm{w})\end{array}$ & $\begin{array}{l}\text { feeding } \\
\text { modality }\end{array}$ & $\begin{array}{c}\text { av. } \\
\text { size } \\
(\mathrm{nm})\end{array}$ & PDI & $\begin{array}{l}\text { Z-pot } \\
(\mathrm{mV})\end{array}$ \\
\hline NP1 & $(-)$ & $\begin{array}{l}\text { 20\% PEGMA } \\
\text { and } \\
5 \% \text { SPMAK }\end{array}$ & MSSEP & 37 & 0.02 & -5.2 \\
\hline NP2 & 0 & $20 \%$ PEGMA $^{a}$ & MSSEP & 40 & 0.07 & -9.6 \\
\hline NP3 & 0 & 20\% PEGMA & MSSEP & 70 & 0.08 & -3.2 \\
\hline NP4 & 0 & 9\% PEGMA & MSSEP & 118 & 0.07 & -2.4 \\
\hline NP5 & + & $20 \%$ MACC & MSSEP & 33 & 0.10 & 39.3 \\
\hline NP6 & + & $10 \%$ MACC & MSSEP & 75 & 0.09 & 42.8 \\
\hline NP7 & + & $5 \%$ MACC & MSSEP & 119 & 0.10 & 35.6 \\
\hline NP8 & - & $20 \%$ SPMAK & MSSEP & 33 & 0.11 & -42.4 \\
\hline NP9 & - & $5 \%$ SPMAK & $\mathrm{BP}$ & 64 & 0.11 & -37.8 \\
\hline NP10 & - & $3 \%$ SPMAK & BP & 117 & 0.14 & -35.3 \\
\hline NP11 & $(+)$ & $\begin{array}{c}25 \% \text { MACC and } \\
11 \% \text { PEGMA }\end{array}$ & MSSEP & 38 & 0.18 & 25.2 \\
\hline
\end{tabular}

${ }^{a}$ Sodium dodecyl sulfate (SDS) $(5 \% \mathrm{w} / \mathrm{w})$ was also added to the surfmer mixture to produce NP2.

$38 \mathrm{~nm}$ ). NP1 presented mostly the same particle size as NP2, with the advantage of avoiding the use of potentially toxic SDS surfactant. NP11 instead was prepared with the aim of exploiting the ability of positively charged groups to enhance cellular uptake, while mitigating their typical cytotoxic behavior with the shielding effect of PEG chains. ${ }^{27}$

For these types of polymeric NPs, particle size and colloidal stability remained unaltered during the in vitro biological tests, as confirmed by previous studies conducted in cell culture media and physiological buffers. ${ }^{17,21}$

Cytotoxicity Tests. Cytotoxicity tests were first carried out to assess which polymeric NP has a safe/toxic effect on podocytes, depending on the size, surface properties, and concentration. SV1 cells were cultured at $37{ }^{\circ} \mathrm{C}$ with a medium containing different concentrations of NPs $(0.01-2 \mathrm{mg} / \mathrm{mL})$ for $24 \mathrm{~h}$. Lactate dehydrogenase (LDH) colorimetric assay was used to quantify the amount of the cytosolic enzyme LDH released by damaged cells as an indicator of cellular toxicity. PEGylated NPs (NP1-NP4) showed a safe cytotoxic profile up to a concentration of $1 \mathrm{mg} / \mathrm{mL}$ (Figure 3A). A slight increase in cytotoxicity was noticed at a concentration of $2 \mathrm{mg} / \mathrm{mL}$ for small-sized NPs (NP1-NP2), which could be ascribed to the co-presence of negatively charged species and PEG macromolecules, as previously discussed. These peculiar surface properties and/or their small size may have a different effect on the cell surface at high concentrations. In the case of positively charged NPs (NP5, NP6, NP7, Figure 3B), a marked cytotoxic effect was already evident at concentrations above $0.2 \mathrm{mg} / \mathrm{mL}$, most likely because of their strong electrostatic interaction with the cell membrane and the consequent damage. ${ }^{28}$ Because of their cytotoxicity, we decided not to use this set of NPs for further study. Negatively charged NPs (NP8, NP9, NP10, Figure $3 \mathrm{C}$ ) showed no cytotoxicity for concentrations up to 0.5 $\mathrm{mg} / \mathrm{mL}$. Above $1 \mathrm{mg} / \mathrm{mL}$, NPs showed a toxic effect, which may be due to the elevated uptake by podocytes (as confirmed afterward in the uptake tests). Cytotoxicity profiles of small PEG-based NPs (NP1, NP2, NP11) are compared in Figure 3D. Whereas NP1 and NP2 showed a very similar trend, NP11 presented high cytotoxicity at a relatively low concentration $(>0.2 \mathrm{mg} / \mathrm{mL})$, suggesting that the presence of positive charges 

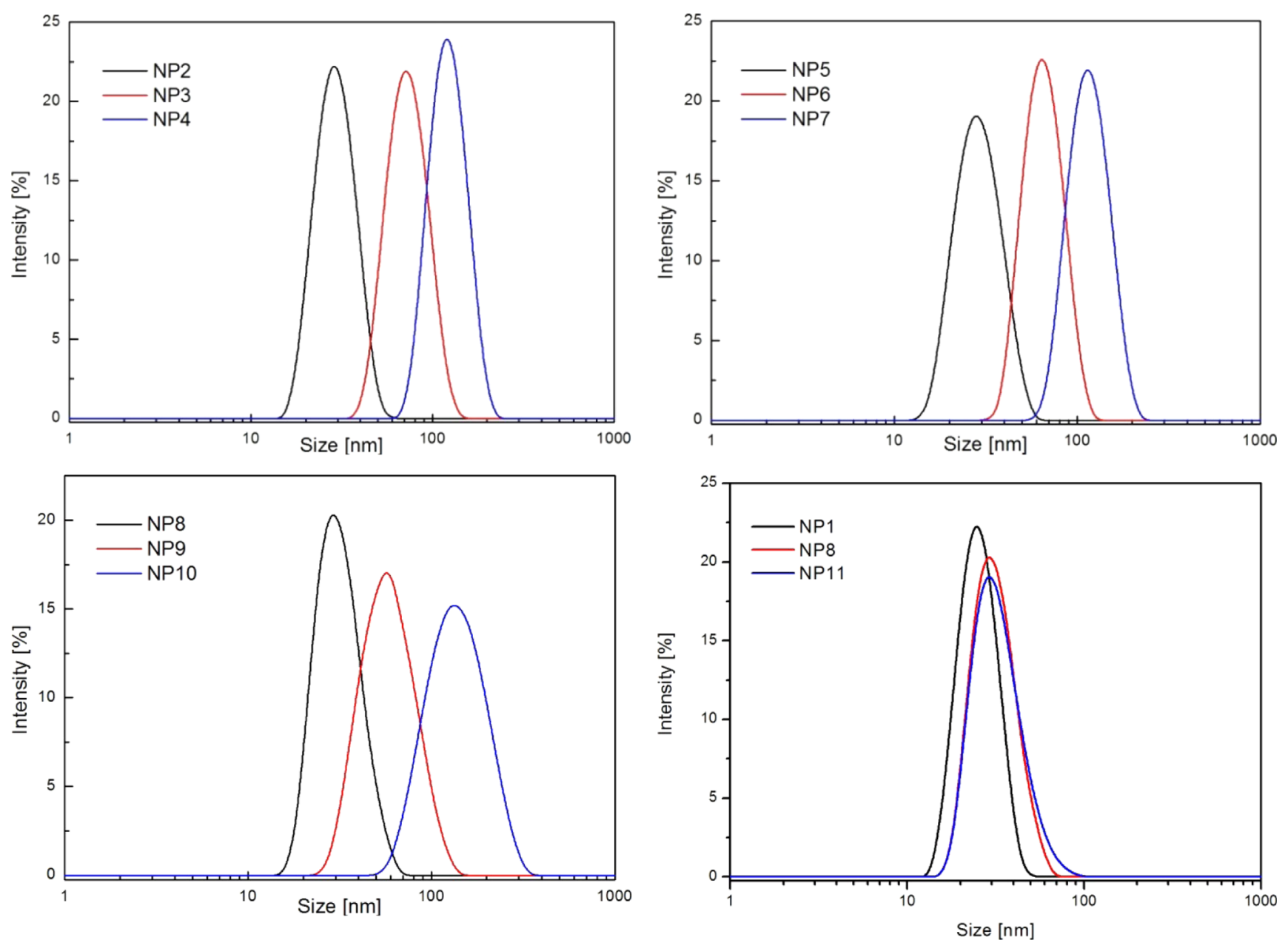

Figure 2. Size distribution curves of NPs NP1-NP11 obtained by DLS analysis.

on NP surface, despite the co-presence of PEG chains, led to cell membrane damage.

Cell Morphology and Cytoskeleton Rearrangement. In addition to cytotoxicity tests, fluorescence microscopy was also necessary to evaluate the effects of NP exposure on the podocyte cytoskeleton, in particular actin fiber rearrangements, as a sign of cellular stress. ${ }^{29,30}$

In fact, recent advances in podocyte biology have pointed out how cell function is strongly dependent on the actin cytoskeleton, ${ }^{31}$ and how actin fiber alterations may be a sign of cell damage triggered by external chemical and biological stimuli. $^{30,31}$

PEGylated NPs do not seem to alter the actin fiber density and orientation significantly, even at high concentrations (up to $1 \mathrm{mg} / \mathrm{mL}$ ) (NP1, Figure 4). On the other hand, negatively charged NPs induced a marked actin rearrangement at high concentrations (NP8, $1 \mathrm{mg} / \mathrm{mL}$, Figure 4). In this case, the actin density decreased around the nucleus, while accumulating near the cell membrane. The fiber rearrangement was associated with considerable NP uptake, demonstrated by the presence of red spots (rhodamine-labeled NPs) within the green phalloidin staining. At lower concentrations $(<0.5 \mathrm{mg} /$ $\mathrm{mL}$ ), negative NPs did not show substantial actin fiber modification, although NP internalization was still significant. Positively charged NPs clearly damaged the cell cytoskeleton at all tested concentrations $(0.05-1 \mathrm{mg} / \mathrm{mL})$, which may be ascribed to the effect of a strong electrostatic interaction between the nanomaterial and cell membrane before internalization. $^{28}$

NP Internalization. A well-established approach based on the selective inhibition of endocytic pathways ${ }^{32}$ was employed to investigate which NP uptake mechanisms were predominantly used by podocytes, depending on the particle size and surface chemistry (Figure 5).

We noticed that the uptake of PEGylated NPs (NP1, NP3, NP4, Figure $5 \mathrm{~A}(\mathrm{a})$ ) was very limited when compared with that of the other types of NPs (Figure $5 \mathrm{~A}(\mathrm{~b})$ ) and that the positively charged NP11 (Figure 5A(c)) showed the highest uptake.

In the case of PEGylated NPs (Figure 5A(a)), a slight decrease in NP uptake by increasing the particle size could be appreciated in the range 30-120 $\mathrm{nm}$. However, the effect of uptake inhibitors was not particularly marked, and this may be due to the low percent uptake measured. Even the sodium azide treatment, which should inhibit all energy-dependent endocytic pathways, did not seem to have a statistically relevant effect.

On the other hand, negatively charged NPs (NP8, NP9, NP10) showed a different trend (Figure 5A(b)). The uptake was enhanced; it was almost 3 times higher for the negatively charged NP8 than that for the PEGylated NP1, although their sizes were approximately the same.

When the particle size was varied, we noticed maximum uptake at the intermediate average diameter (NP9, $64 \mathrm{~nm})$, 


\section{A}

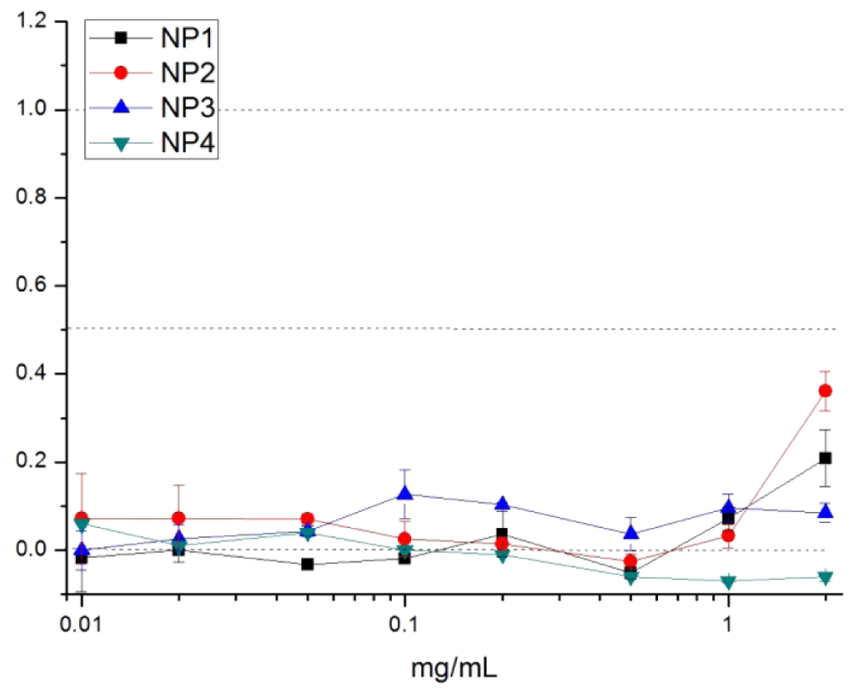

C

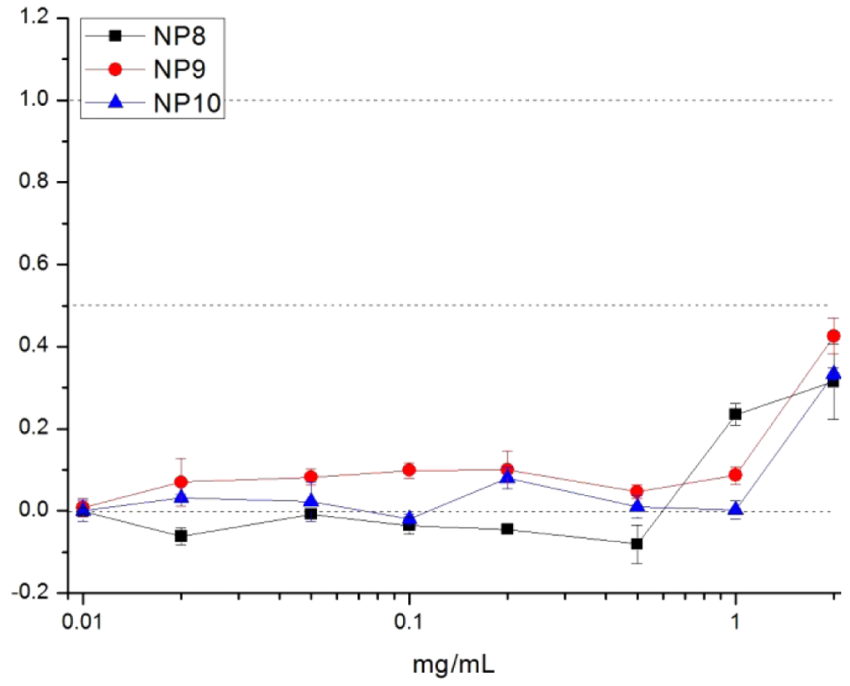

B

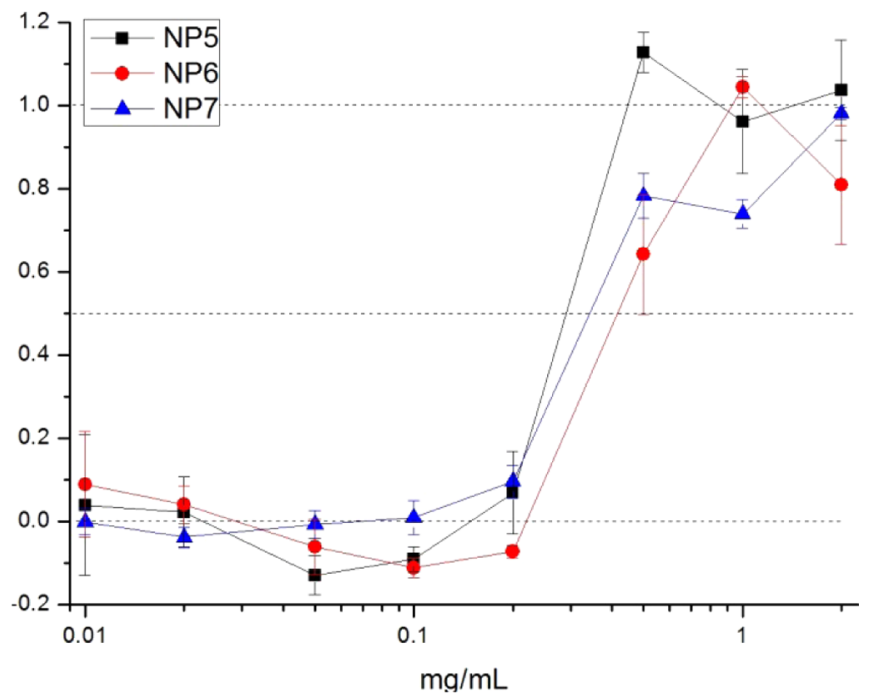

D

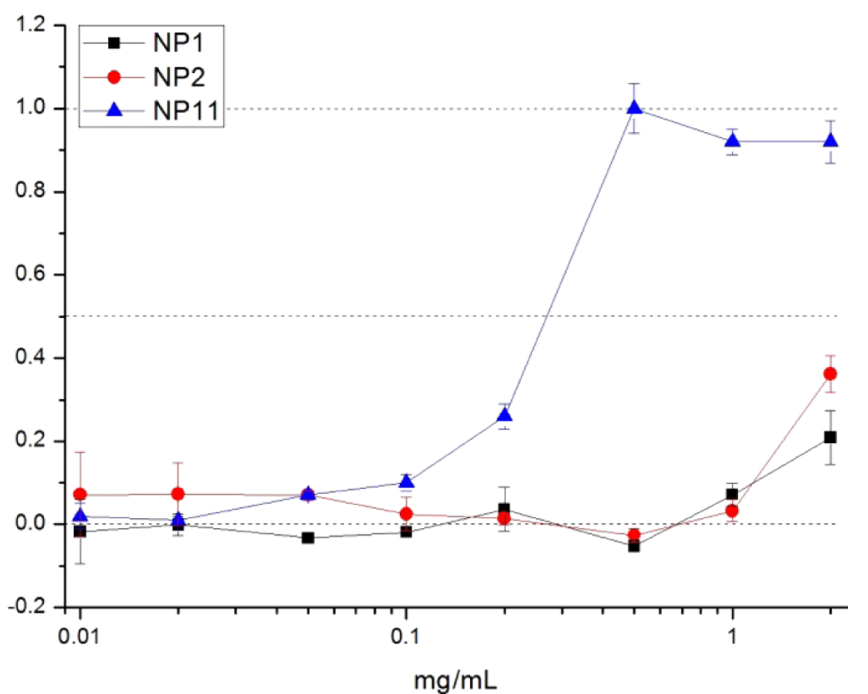

Figure 3. LDH assay on murine podocytes (SV1) incubated with NP1-NP11 NPs (NP1-NP4 (A), NP5-NP7 (B), NP8-NP10 (C), NP1-NP2$\mathrm{NP11}(\mathrm{D})$ ) for $24 \mathrm{~h}$, at concentrations from 0.01 to $2 \mathrm{mg} / \mathrm{mL}$ ( $Y$ axis: normalized cytotoxicity).

which might be interpreted as a sign of a preferential endocytic mechanism. In fact, caveolae typically appear as rounded plasma membrane invaginations with diameters of $50-80 \mathrm{~nm}^{33}$ although other works suggested that the pit diameter may not be the limiting factor in the pathway selection of NP entry into cells. ${ }^{34,35}$ Anyway, the clear inhibition effect of Genistein supported the hypothesis of a caveolin-dependent endocytosis, whereas inhibition of clathrin-dependent uptake (chlorpromazine) showed a very limited effect. The presence of an energydependent endocytic mechanism was confirmed by particle uptake decrease after $\mathrm{NaN}_{3}$ treatment, which was apparent for all negatively charged NPs (NP8, NP9, NP10), and in particular, for particles larger than $30 \mathrm{~nm}$. There was no evidence of micropinocytosis (wortmannin inhibition). Moreover, the absence of effects of bafilomycin Al could indicate a nonreceptor-mediated process, ${ }^{36}$ as expected.

Positively charged NP11 (Figure 5A(c)) showed a similar trend to that in negative NPs but with much higher percent uptake (about 6 times higher than that of PEG-NP and 2 times higher than that of the negative NP). In this case, the internalization seemed to be energy dependent and followed preferentially a caveolin pathway. Notably, together with the electrostatic interactions between this type of NPs and cell membrane, adsorption of the negatively charged albumin present in the FBS of the medium may also take place; this could regulate NP interfacing with the cell membrane and trigger an energy-dependent endocytosis. ${ }^{37}$ The effect of NP concentration on the internalization process was also assessed (see the Supporting Information).

Figure 5B shows how the NP uptake followed a typical endosomal pathway, particularly for negatively charged NPs. Fluorescently labeled small PEGylated NPs (NP1, red) did not show strong evidence of co-localization with the endosomal compartments stained with lysotracker green (Figure $5 \mathrm{~B}(\mathrm{a}, \mathrm{b})$ ). This result may be due to the very limited internalization of PEG-based NPs. On the other hand, small negatively charged NPs (NP8) showed clear co-localization (orange color, Figure $5 \mathrm{~B}(\mathrm{c}, \mathrm{d})$ ), which persisted even after $48 \mathrm{~h}$. 


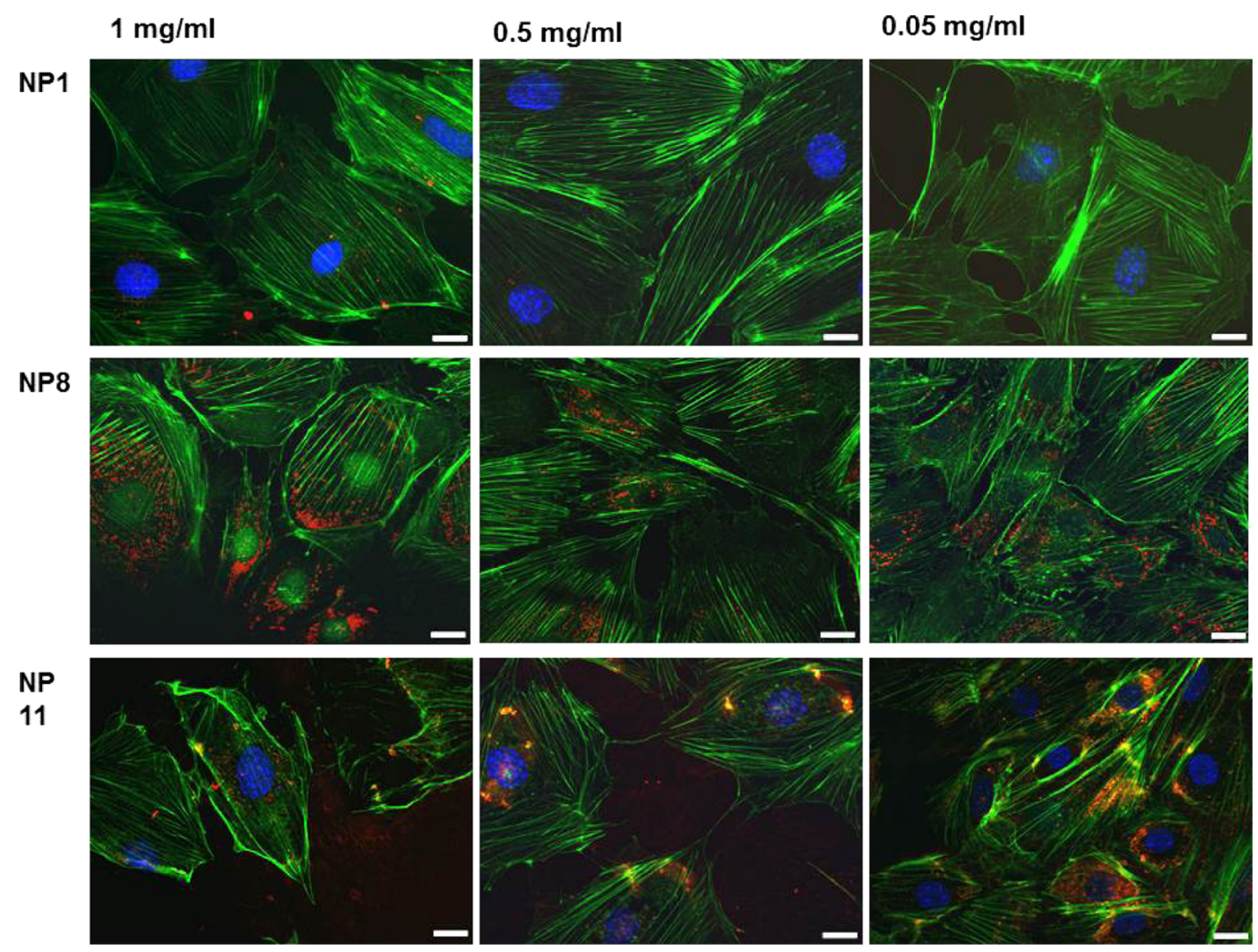

Figure 4. Phalloidin staining (green) of filamentous actin in podocytes after $24 \mathrm{~h} \mathrm{NP}$ exposure (NP1, NP8, NP11, red staining) at different concentrations $(1,0.5$, and $0.05 \mathrm{mg} / \mathrm{mL})$. Scale bar $20 \mu \mathrm{m}$.

In summary, we identified the surface properties of the NPs (charge, PEGylation) as the dominant factors that affect both nanotoxicity and uptake on podocytes. Once cell-particle interactions are guaranteed by their surface, the particle size may also play a role in promoting specific endocytic pathways, thus influencing the uptake.

In Vitro Release of Dexamethasone (DEX). Taking into account the marked ability of podocytes to interact with engineered polymeric NPs and internalize them according to their physicochemical characteristics, we investigated the effect of drug-loaded NPs on podocyte repair, aiming at designing novel polymeric nanocarriers, which may potentially target podocytes in proteinuric diseases. The sustained therapeutic effects of nanoencapsulated drugs were demonstrated on cultures of podocytes, whose damage was induced in vitro by incubation with Adriamycin (doxorubicin hydrochloride) for 24 h. ${ }^{29,30}$ Damaged podocytes displayed shortened cell processes and substantial remodeling of the actin cytoskeleton, with loss of filament bundles and rounding of the cell shape ${ }^{30}$ (Figure 7). DEX was chosen as the model drug for loading and release, first because it is a steroid with a proved efficacy in repairing podocytes $^{38,39}$ (although literature data are generally referred to the water-soluble DEX phosphate) and second because its low molecular weight and high hydrophobicity are key characteristics for efficient encapsulation in these types of polyesterbased NPs, ${ }^{40}$ through interaction with the hydrophobic poly $(\varepsilon$ caprolactone) core. A set of four different NPs, having two different sizes (30 and $120 \mathrm{~nm}$ ) and either PEGylated or negatively charged (i.e., NP1, NP4, NP8, NP10), was chosen for drug delivery tests. Positively charged NPs, including NP11, were not taken into account because of their high cell toxicity.
Because high temperature and the presence of radicals were unsuitable conditions for simultaneous drug loading during NP synthesis, a postsynthesis swelling/diffusion encapsulation method $^{20}$ was optimized for this study (see the Methods section). We obtained for each type of NP a target value of 50 $\pm 1 \mu \mathrm{g}$ of DEX encapsulated per $\mathrm{mg}$ of dry polymer (as determined by high-performance liquid chromatography (HPLC)). Drug release tests were carried out under sink conditions in phosphate-buffered saline (PBS) at $37^{\circ} \mathrm{C}$. Release profiles were followed by HPLC and are shown in Figure 6. The drug release mechanism was purely diffusive, and polymer degradation had no influence within the time scale of the experiment. ${ }^{17,21,41}$ Clearly, small NPs (NP1, NP8) presented a faster release due to their higher surface area per mg of polymer compared to bigger NPs. In fact, NP4 and NP10 reached $97 \%$ release in $72 \mathrm{~h}$, whereas NP1 and NP8 achieved $100 \%$ release in $24 \mathrm{~h}$. Moreover, NPs having the same size but different surface properties showed a very similar release curve; this result suggested that the DEX release mechanism was not significantly influenced by the presence of a PEG corona.

Although the NPs presented a relatively fast drug release profile (release curves plateaued at 24-72 h, depending on the particle size), these results may be compatible with targeted drug delivery to the kidneys, taking into account that a more sustained delivery would be outweighed by the high turnover of fluids in kidney glomeruli (the renal blood flow is approximately $20 \%$ of the cardiac output, corresponding to a glomerular filtration rate of $1.2 \mathrm{~L} / \mathrm{min}$, and the total glomerular filtrate in $24 \mathrm{~h}$ is $50-60$ times the volume of blood plasma in adults ${ }^{42}$ ).

The effect of DEX release by the NPs is summarized in Figure 7. Cytoskeleton damage, triggered by Adriamicyn, was 
A

a

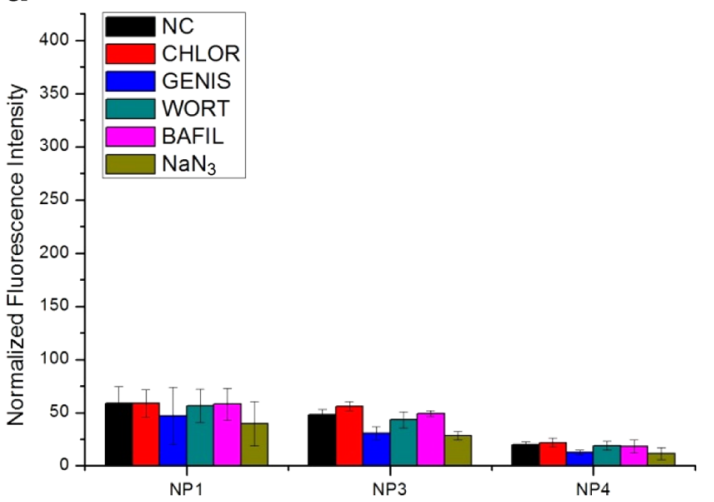

b

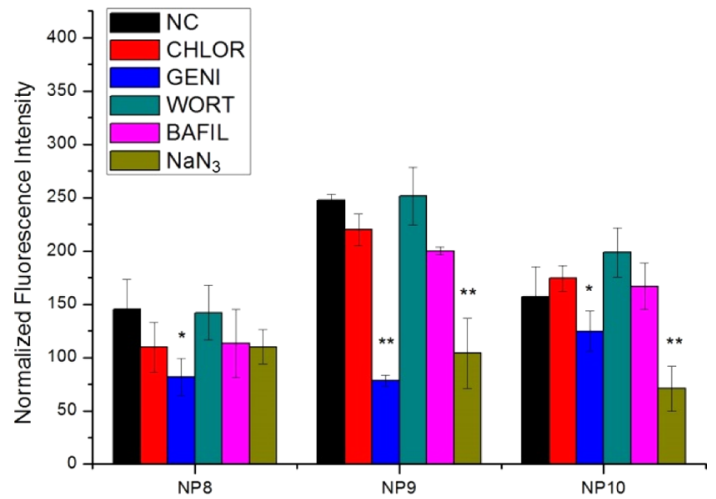

C

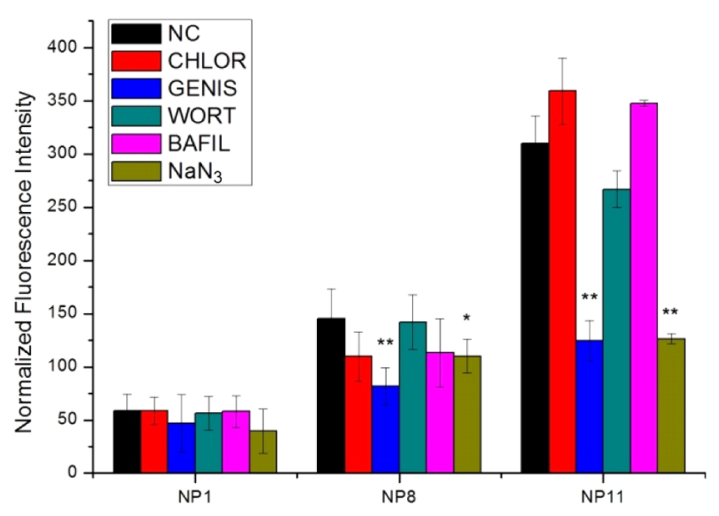

B
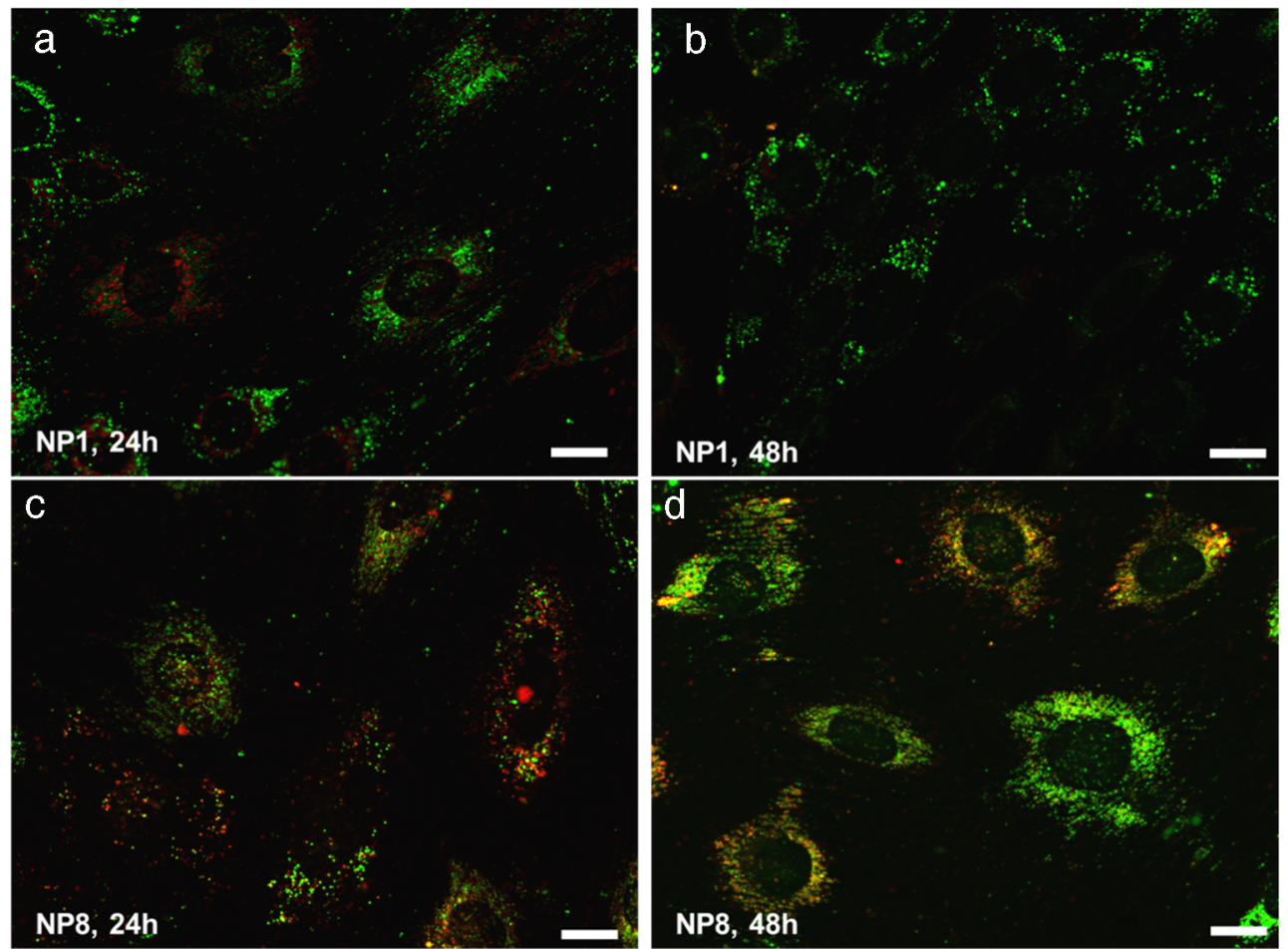

Figure 5. (A) Effect of endocytosis inhibitors on $24 \mathrm{~h}$ NP uptake (NP1-NP3-NP4 (a), NP8-NP9-NP10 (b), NP1-NP8-NP11 (c), particle concentration $0.5 \mathrm{mg} / \mathrm{mL}$ ) (NC, negative control; CHLOR, chlorpromazine; GENIS, Genistein; WORT, Wortmannin; BAFIL, Bafilomycin A1; $\mathrm{NaN}_{3}$, sodium azide). $* P<0.05, * * P<0.01$. (B) Localization of rhodamine-labeled NPs (red) in relation to endolysosomes (green, LysoTracker green) in SV1 podocytes. NP1 (PEGylated $37 \mathrm{~nm}, 0.5 \mathrm{mg} / \mathrm{mL}$ ) and NP8 (sulfonate, $30 \mathrm{~nm}, 0.5 \mathrm{mg} / \mathrm{mL}$ ) were incubated for $24 \mathrm{~h}(\mathrm{a}, \mathrm{c}$ ) and their localization visualized just after NP incubation and after $48 \mathrm{~h}$ (b, d). Scale bar $20 \mu \mathrm{m}$. 


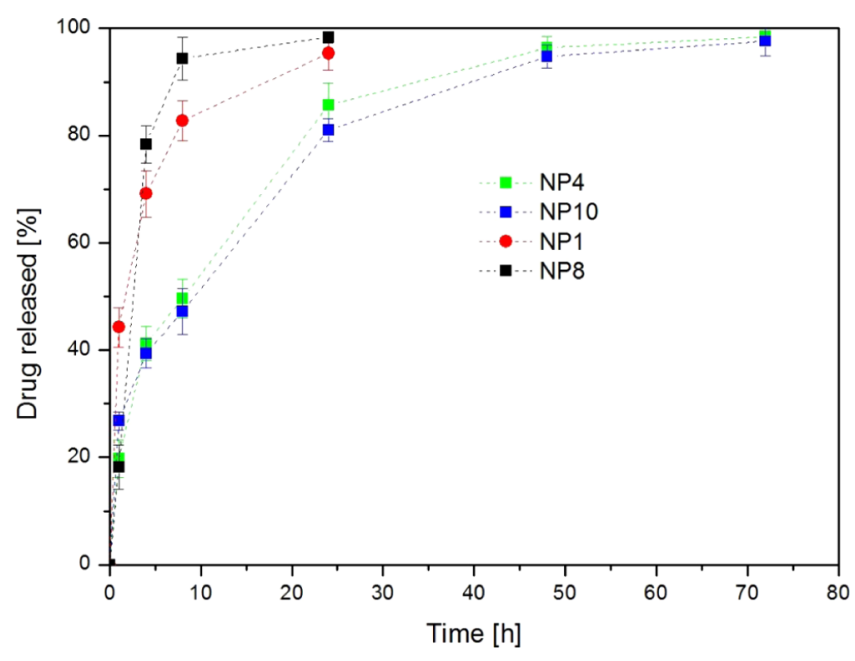

Figure 6. DEX release from NPs NP1, NP4, NP8, and NP10 in PBS at $37^{\circ} \mathrm{C}$. Error bars indicate $\pm \mathrm{SD}$ from experiments run in triplicate.

highlighted by staining the actin fibers (green phalloidin) and observing that they were mostly localized in the proximity of the cell membrane and their density was reduced within the cell body and around the nucleus. When damaged cells were treated with DEX-loaded PEGylated NPs (NP4, $20 \mu \mathrm{g} / \mathrm{mL}$, loaded with DEX 5\% w/w) for $24 \mathrm{~h}$, they started recovering the normal orientation of actin stress fibers (Figure 7A), a process which was almost completed in $48 \mathrm{~h}$. A very similar trend was observed with negatively charged NPs (NP10, the same size as NP4) but with a much higher internalization (see red spots within the cytosolic space). On the other hand, at higher NP concentrations $(1 \mathrm{mg} / \mathrm{mL}$ ), the toxic effect (which perhaps was also enhanced by the presence of a high drug concentration) of NP10 as well as NP4 overwhelmed the repairing effect of DEX.

Treatment with DEX-loaded small NPs NP1 and NP8 (size 37 and $33 \mathrm{~nm}$, respectively) showed very similar results to those obtained with the larger NP4 and NP10 (Figure 7B). At $1 \mathrm{mg} / \mathrm{mL}$ concentration, both PEGylated and negatively charged NPs showed some toxic effects, in particular a large amount of NP8 were internalized. At a low concentration (0.02 $\mathrm{mg} / \mathrm{mL}$ ), the toxic effect was reduced and DEX release triggered recovery of actin fiber density and orientation. The use of small NPs is clearly preferred for possible future in vivo application because reduced size would facilitate drug permeation through the kidney filtration barrier, thus reaching the podocyte layer more efficiently. ${ }^{43}$ In this case (Figure 7B), we also noticed a marked recovery of actin fiber orientation and density already after $24 \mathrm{~h}$ incubation with NP8, whereas with
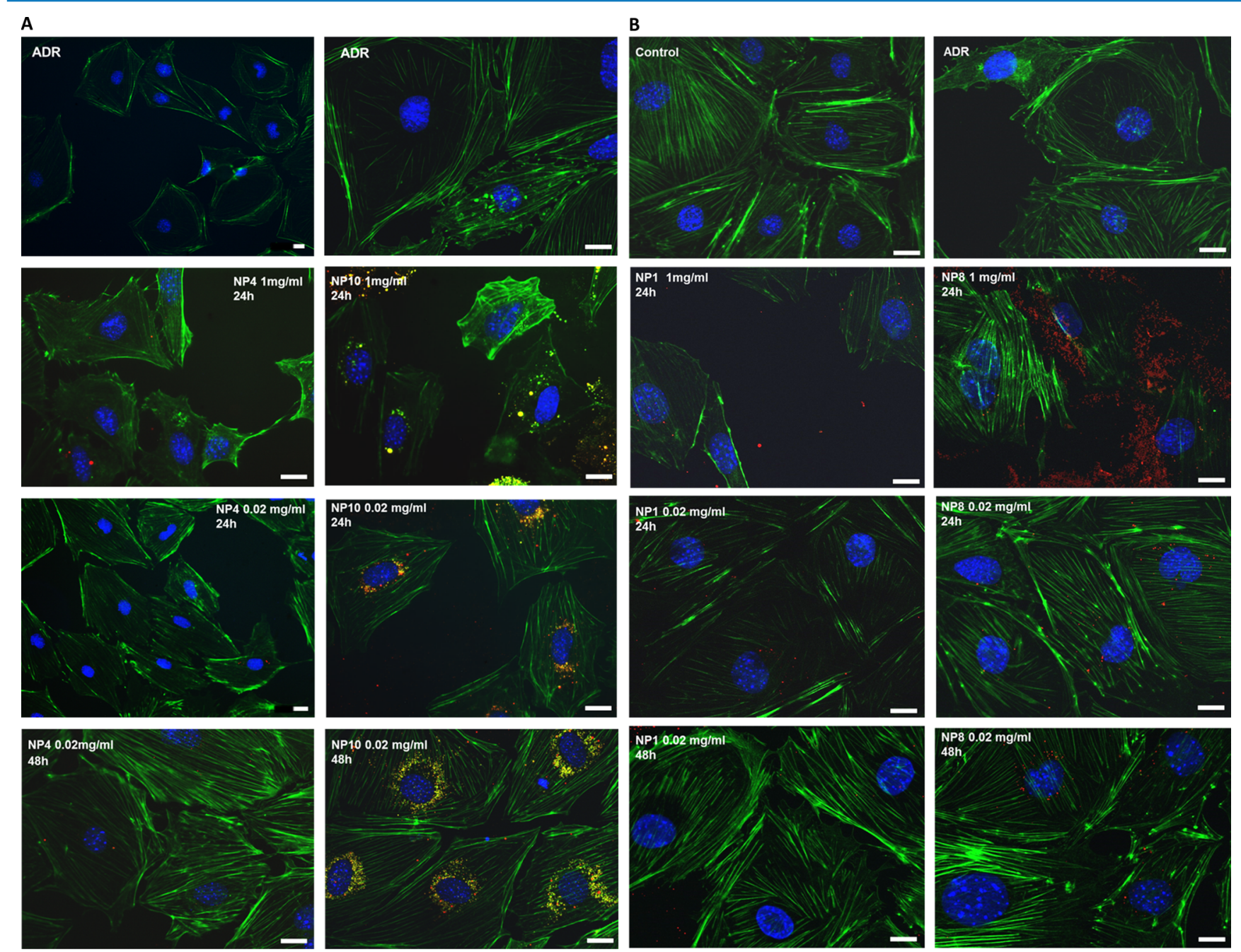

Figure 7. Podocytes were first damaged by ADR, then treated for 24 and $48 \mathrm{~h}$ with DEX-loaded large NPs (NP4, NP10) (A) and small NPs (NP1, NP8) (B), at two different concentrations ( $1 \mathrm{mg} / \mathrm{mL}$ and $20 \mu \mathrm{g} / \mathrm{mL})$. DEX (5\% w/w), scale bar $20 \mu \mathrm{m}$. 
A

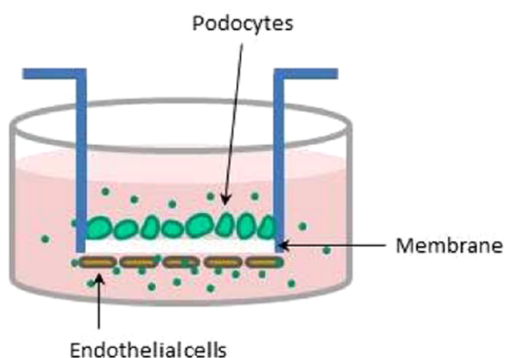

Endothelialcells
B

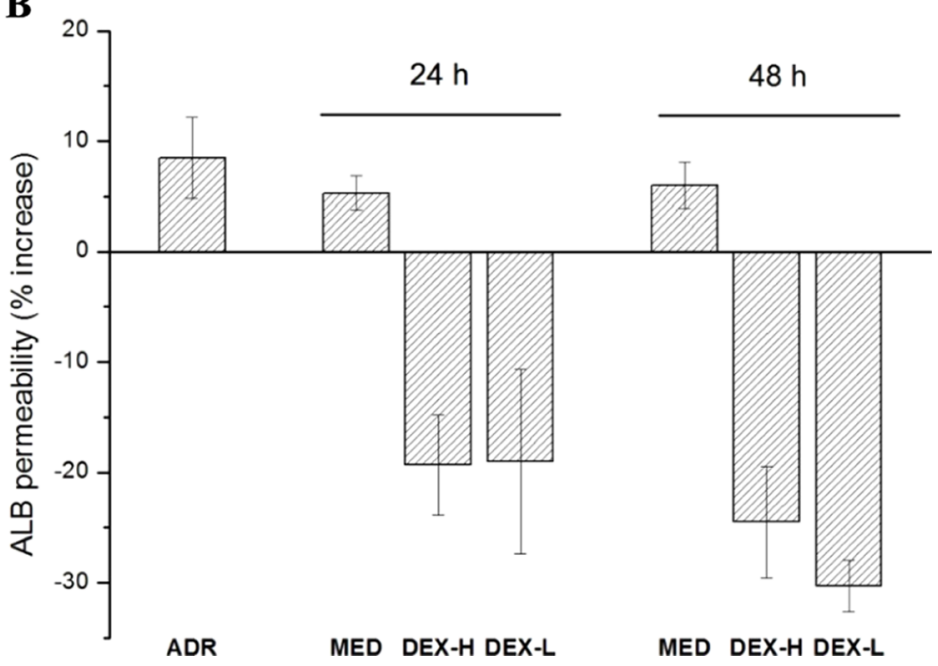

Figure 8. (A) Sketch of the 3D co-culture system designed to mimic glomerular filtration barrier in vitro. (B) Percent increase of albumin (ALB) permeability following Adriamycin treatment (ADR), and recovery by 24 and $48 \mathrm{~h}$ of incubation with standard medium (MED) and DEX-loaded NP8 at a high concentration (DEX-H; NP8 $1 \mathrm{mg} / \mathrm{mL}+\mathrm{DEX} 5 \% \mathrm{w} / \mathrm{w}$, corresponding to $100 \mu \mathrm{M}$ ) and a low concentration (DEX-L; NP8 0.02 mg/ $\mathrm{mL}+\mathrm{DEX} 5 \% \mathrm{w} / \mathrm{w}$ corresponding to $2 \mu \mathrm{M})$.

NP1, the effect was pronounced only after $48 \mathrm{~h}$. These results may be ascribed to a much higher internalization of negatively charged NPs, which allowed better intracellular release of DEX, and therefore, an enhanced repairing effect of the drug, whose receptors reside in the cytosol. ${ }^{39}$

In Vitro Drug Testing in a 3D Co-culture System. Nanodelivery of DEX was also successful in repairing damaged co-cultures of endothelial cells and podocytes, which were exploited as a tool for mimicking the glomerular filtration barrier in vitro.

The 3D co-culture model is based on an isoporous $(1 \mu \mathrm{m}$ pore size) poly(ethylene terephthalate) membrane insert, coated on both sides with collagen type IV, and finally covered with podocytes and endothelial cells on the respective external and internal sides ${ }^{18,19}$ (Figure 8A). The presence of the membrane between the two cell types permits performing separate assays in the two compartments and allows the functional assessment of albumin permeability through the membrane.

To establish whether this model could be useful in testing our NP-based drug delivery system, the co-culture was pretreated with Adriamycin to induce cellular damage and increase albumin permeability. Afterward, the membrane was incubated with DEX-loaded NP8 NPs, that is, the NP type showing the best performance in terms of low cytotoxicity, high uptake, DEX release, and podocyte-repairing effect in a $2 \mathrm{D}$ culture system.

NP concentrations were selected to achieve an optimal DEX concentration range below $100 \mu \mathrm{M}$, that is, concentrations already reached in humans after intravenous injection and oral administration. $^{44}$

NP treatment led to progressive reduction of albumin permeability that was not observed with medium alone at 24 and $48 \mathrm{~h}$ of incubation (Figure $8 \mathrm{~B}$ ). In particular, a low concentration of NPs $(0.02 \mathrm{mg} / \mathrm{mL}$, which encapsulated $5 \% \mathrm{w} /$ $\mathrm{w}$ of DEX, corresponding to $2 \mu \mathrm{M}$ in the co-culture system) achieved a reduction in albumin permeability, which was comparable to the response to a high NP concentration (1 mg/ $\mathrm{mL}$, corresponding to $100 \mu \mathrm{M}$ in the co-culture system). This may indicate either the presence of a concentration threshold, above which cells respond in a similar way, or a more complex balance between the DEX effects and toxic effects of the polymeric nanomaterial at higher concentrations.

It is noteworthy that the incubation with these DEX-loaded NPs did not return albumin permeability to its initial value (prior Adriamycin treatment), but markedly reduced it below the control values. This result could be ascribed to the role of DEX in stimulating better cellular layer organization, with a consequent decrease in the membrane pore size/number.

\section{CONCLUSIONS}

Engineered polymeric NPs of tuneable size and surface properties were successfully produced and used to evaluate their interactions with kidney podocytes in vitro. The cytotoxicity, uptake, and cytoskeleton stress were markedly dependent on the particle size, surface charge, and PEG corona. Damaged podocytes were successfully repaired with controlled nanodelivery of DEX, in view of developing new kidney-specific nanotherapeutics. A 3D co-culture system based on endothelial cells and podocytes was also employed to study the mechanisms of NP interaction with glomerular cells and the repair of a podocyte-endothelium membrane, designed to mimic the kidney filtration barrier in vitro.

\section{METHODS}

NP Synthesis, Drug Loading, and in Vitro Release. Materials, synthesis of the HEMA-CL $\mathrm{CL}_{3}$ macromonomer, and synthesis of the fluorescent HEMA-RhB monomer are reported in the Supporting Information.

Synthesis of Polyester-Based NPs. NP synthesis was carried out in a three-neck flask, equipped with a condenser, containing $49 \mathrm{~mL}$ of distilled water; the system was purged through repeated vacuum-nitrogen cycles and kept at $80{ }^{\circ} \mathrm{C}$ through the use of an external oil bath. Depending on the target particle size and surface charge, different surfmers (PEGMA, SPMAK, and MACC), macromonomer/surfmer mass ratios, and either BEP or MSSEP were used, as summarized in Table 1. In BEP, the macromonomer, HEMA- $\mathrm{CL}_{3}$, and the surfmer were loaded together into the reactor, whereas in MSSEP, the water-soluble surfmer was added into the reactor, whereas the 
hydrophobic HEMA- $\mathrm{CL}_{3}$ macromonomer was fed using a syringe pump (model NE 300; New Era Pump System, the flow rate was changed for each sample to maintain the feeding equal to $1 \mathrm{~h}) .{ }^{17}$ One gram of total monomer mixtures (macromonomer and surfmer) was used for all reactions, unless specifically noted; $0.1 \% \mathrm{w} / \mathrm{w}$ HEMA-RhB was also added when fluorescently labeled NPs were required for biological experiments.

KPS (20 mg) was used as the initiator for synthesizing negatively charged and PEGylated NPs, whereas $20 \mathrm{mg}$ of AAPH was employed for positively charged NPs. In all cases, the reaction was carried out for $3 \mathrm{~h}$, and before any further use, NPs were dialyzed (3500 Da cutoff membranes) against PBS buffer $(10 \mathrm{mM})$ to remove any possible impurities. The particle size distribution, average size, PDI, and Z-potential of the final products were evaluated via DLS (Malvern Zetasizer Nano). TEM samples of selected NP latexes were investigated on a Zeiss EFTEM Leo 912AB transmission electron microscope working at $80 \mathrm{kV}$. The sample was prepared by placing a $5 \mu \mathrm{L}$ drop of NP colloidal suspension on a Formvar/carbon-coated copper grid and was dried overnight. Digital images were acquired by a charge-coupled device Esi Vision Proscan camera.

Drug Loading and in Vitro Release. NP latexes (NP1, NP8, NP4, NP10) were concentrated up to $5 \% \mathrm{w} / \mathrm{w}$ under a rotavapor, and DLS analysis confirmed the absence of aggregation. DEX was dissolved in dimethyl sulfoxide (DMSO) $(20 \mathrm{mg} / \mathrm{mL})$ under gentle magnetic stirring at room temperature. The two phases (NP latex and drug in DMSO) were injected axially into a poly(tetrafluoroethylene) mixing device ${ }^{20}$ at a flow rate of 30 and $5 \mathrm{~mL} / \mathrm{min}$, respectively. DEX-loaded NPs were collected from the mixer outlet, and the absence of DEX aggregates was confirmed by DLS.

The drug-loading efficiency was evaluated by placing drugloaded NP latexes in centrifugal filters (Amicon Ultra, $100 \mathrm{kDa}$ cutoff), which were centrifuged at $4500 \mathrm{rpm}$ for $15 \mathrm{~min}$ to separate the NPs from the supernatant and the free drug. The final concentration of free drug in the supernatant was

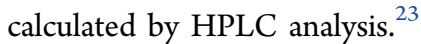

Release studies were conducted via HPLC by dialyzing $3 \mathrm{~mL}$ of DEX-loaded NPs against $200 \mathrm{~mL}$ of PBS buffer at $37^{\circ} \mathrm{C}$ with Slyde A Lyzer Dialysis cassettes (Thermo Scientific, 3500 Da cutoff). At selected times, small aliquots $(50 \mu \mathrm{L})$ were withdrawn and replaced with an equal volume of PBS. These aliquots were dried under a nitrogen stream and extracted with a fixed volume of acetonitrile under vortex mixing. After centrifugation at $4000 \mathrm{rpm}$ for $10 \mathrm{~min}$, the supernatant was injected into the HPLC system (Agilent 1200 series) equipped with a UV-vis detector $(\lambda=250 \mathrm{~nm})$; the mobile phase was composed of water and acetonitrile $(70 / 30 \mathrm{v} / \mathrm{v})$ under isocratic conditions at a flow rate of $1.5 \mathrm{~mL} / \mathrm{min}$ (DEX elution time 10 $\min$ ).

Before in vitro experiments, $3 \mathrm{~mL}$ of the selected DEXloaded NPs were dialyzed against $200 \mathrm{~mL}$ of PBS to remove solvent and impurities from the formulations.

LDH Cytotoxicity. The NP cytotoxicity was measured using an LDH-Cytotoxicity Colorimetric Assay Kit (BioVision Incorporated), which was used according to supplier's protocol (experimental details are reported in the Supporting Information).

Fluorescence Microscopy Examination. Conditionally immortalized murine kidney podocytes SV1 (CLS Cell Line Service Ltd, Eppelheim, Germany) were cultured on coverslips and fixed with $4 \%$ of paraformaldehyde at room temperature for $10 \mathrm{~min}$. After washing, cells were permeabilized with $0.3 \%$ of Triton in PBS for $5 \mathrm{~min}$ and incubated with $1 \%$ of bovine serum albumin in PBS at room temperature for $30 \mathrm{~min}$. Phalloidin-FITC (Sigma-Aldrich) at 1:100 dilution together with DAPI at 1:1000 dilution (Sigma-Aldrich) was added, and the cells were incubated for $1 \mathrm{~h}$. After 3 times washing with PBS, the cells were mounted with Fluorsave aqueous mounting medium (Merck, Milano, Italy). Images were acquired using a Zeiss AxioObserver microscope equipped with a highresolution digital videocamera (AxioCam, Zeiss) and an Apotome system for structured illumination, and recorded by the AxioVision software, version 4.8 .

NP Uptake. SV1 cells (6000-8000 per well) were plated on a 96-well black plate and cultured at $37^{\circ} \mathrm{C}$ without $\gamma$-interferon for 3-4 days. Then, the culture medium was replaced by medium containing different endocytosis inhibitors (Chlorpromazine $10 \mu \mathrm{g} / \mathrm{mL}$; Genistein $200 \mu \mathrm{M}$; Wortmannin $100 \mathrm{nM}$; Bafilomycin A1 $200 \mathrm{nM}$; Sodium azide $10 \mathrm{mM}$, all purchased from Sigma), which were preincubated with the cells for 30 min. After $30 \mathrm{~min}$ preincubation, NP1-NP11 were added at a concentration of $0.5 \mathrm{mg} / \mathrm{mL}$, alone or together with the inhibitors, and incubated with cells for $24 \mathrm{~h}$. At the end of incubation, the supernatants were removed, and the cells were thoroughly washed thrice with PBS. The intracellular NP was measured using SAFAS spectrophotometry at an excitation wavelength of $540 \mathrm{~nm}$ and an emission wavelength of $584 \mathrm{~nm}$. Janus Green cell normalization stain was used to adjust the cell plating difference among the wells. NP-lysosome co-localization was characterized by incubating the cells with LysoTracker green (Life technologies) at a concentration of $666 \mathrm{nM}$ together with Hoechst 33342 (Life technologies) at a concentration of $5 \mu \mathrm{g} / \mathrm{mL}$ in culture medium for $1 \mathrm{~h}$. At the end of incubation, the staining solution was replaced with fresh medium without phenol red, and the cells were observed using a Zeiss AxioObserver microscope.

DEX Release on Podocytes. SV1 cells (20000) were plated on a $35 \mathrm{~mm}$ Petri dish containing four cell culture coverslips and cultured at $37{ }^{\circ} \mathrm{C}$ without $\gamma$-interferon for 3-4 days. Afterwards, cells were incubated with $0.8 \mu \mathrm{M}$ Adriamycin (ADR, Sigma-Aldrich) in cell culture medium for $24 \mathrm{~h}$. After 24 $\mathrm{h}$ incubation, ADR was replaced by fresh medium (as the control group) or medium with a different concentration of NPs loaded with DEX and incubated for another 24 or $48 \mathrm{~h}$. Cells were finally washed thrice with PBS and characterized by fluorescence microscopy, as described above.

Co-Culture System and Assessment of Permeability. Preparation of the three-dimensional podocyte-endothelial cell co-cultures and protein permeability assessment were carried out according to a previously reported procedure. ${ }^{19}$ Experimental conditions for Adriamicin treatment and NP incubation are described in the Supporting Information.

\section{ASSOCIATED CONTENT}

\section{Supporting Information}

The Supporting Information is available free of charge on the ACS Publications website at DOI: 10.1021/acsomega.6b00423.

Materials, synthesis, and characterization of the HEMA$\mathrm{CL}_{3}$ macromonomer and HEMA-RhB monomer, polymer characterization, TEM characterization, LDH cytotoxicity, NP uptake, co-culture system and assessment of permeability, stability of fluorescent NPs with podocytes at different incubation times (PDF) 


\section{AUTHOR INFORMATION}

\section{Corresponding Author}

*E-mail: francesco.cellesi@polimi.it.

ORCID $\odot$

Davide Moscatelli: 0000-0003-2759-9781

Francesco Cellesi: 0000-0001-6106-9317

\section{Present Addresses}

"Department of Pediatrics, Hirosaki University Hospital, 53 Honcho, Hirosaki 036-8563, Aomori, Japan (S.W.).

${ }^{\perp}$ Institute for Chemical and Bioengineering (ICB), ETH Zurich, Vladimir Prelog Weg 1, Zürich 8093, Switzerland (C.C.).

\section{Notes}

The authors declare no competing financial interest.

\section{ACKNOWLEDGMENTS}

Financial support from Fondazione CEN - European Centre for Nanomedicine (Start-up package grant), co-funded by Regione Lombardia through the "Fondo per lo sviluppo e la coesione 2007-2013", is gratefully acknowledged. This work was also supported by Fondazione Cariplo (grant no. 20131047, Nanoparticelle - 2013), by Associazione Bambino Nefropatico ABN ONLUS, Milano, Italy, and by Fondazione La Nuova Speranza, Lotta alla Glomerulosclerosi Focale, Rho, $\mathrm{Mi}$, Italy.

\section{REFERENCES}

(1) Pollinger, K.; Hennig, R.; Breunig, M.; Tessmar, J.; Ohlmann, A.; Tamm, E. R.; Witzgall, R.; Goepferich, A. Kidney Podocytes as Specific Targets for cyclo(RGDfC)-Modified Nanoparticles. Small 2012, 8, $3368-3375$.

(2) Nair, A. V.; Keliher, E. J.; Core, A. B.; Brown, D.; Weissleder, R. Characterizing the Interactions of Organic Nanoparticles with Renal Epithelial Cells in Vivo. ACS Nano 2015, 9, 3641-3653.

(3) Choi, C. H. J.; Zuckerman, J. E.; Webster, P.; Davis, M. E. Targeting kidney mesangium by nanoparticles of defined size. Proc. Natl. Acad. Sci. U.S.A. 2011, 108, 6656-6661.

(4) L’Azou, B.; Jorly, J.; On, D.; Sellier, E.; Moisan, F.; Fleury-Feith, J.; Cambar, J.; Brochard, P.; Ohayon-Courtès, C. In vitro effects of nanoparticles on renal cells. Part. Fibre Toxicol. 2008, 5, 1-14.

(5) Miladi, I.; Le Duc, G.; Kryza, D.; Berniard, A.; Mowat, P.; Roux, S.; Taleb, J.; Bonazza, P.; Perriat, P.; Lux, F.; Tillement, O.; Billotey, C.; Janier, M. Biodistribution of ultra small gadolinium-based nanoparticles as theranostic agent: Application to brain tumors. J. Biomater. Appl. 2013, 28, 385-394.

(6) Cellesi, F.; Li, M.; Rastaldi, M. P. Podocyte injury and repair mechanisms. Curr. Opin. Nephrol. Hypertens. 2015, 24, 239-244.

(7) Schoenenberger, E.; Ehrich, J. H.; Haller, H.; Schiffer, M. The podocyte as a direct target of immunosuppressive agents. Nephrol., Dial., Transplant. 2011, 26, 18-24.

(8) Kriz, W. Podocytes as a target for treatment with ACE inhibitors and/or angiotensin-receptor blockers. Kidney Int. 2004, 65, 333-334.

(9) Fornoni, A.; Sageshima, J.; Wei, C.; Merscher-Gomez, S.; Aguillon-Prada, R.; Jauregui, A. N.; Li, J.; Mattiazzi, A.; Ciancio, G.; Chen, L.; Zilleruelo, G.; Abitbol, C.; Chandar, J.; Seeherunvong, W.; Ricordi, C.; Ikehata, M.; Rastaldi, M. P.; Reiser, J.; Burke, G. W., III Rituximab Targets Podocytes in Recurrent Focal Segmental Glomerulosclerosis. Sci. Transl. Med. 2011, 3, No. 85ra46.

(10) Sarhan, O. M.; Hussein, R. M. Effects of intraperitoneally injected silver nanoparticles on histological structures and blood parameters in the albino rat. Int. J. Nanomed. 2014, 9, 1505-1517.

(11) Xu, J.; Li, Z.; Xu, P.; Xiao, L.; Yang, Z. Nanosized copper oxide induces apoptosis through oxidative stress in podocytes. Arch. Toxicol. 2013, 87, 1067-1073.
(12) Xu, P.; Xu, J.; Liu, S.; Yang, Z. Nano copper induced apoptosis in podocytes via increasing oxidative stress. J. Hazard. Mater. 2012, 241-242, 279-286.

(13) Iversen, N. K.; Frische, S.; Thomsen, K.; Laustsen, C.; Pedersen, M.; Hansen, P. B. L.; Bie, P.; Fresnais, J.; Berret, J.-F.; Baatrup, E.; Wang, T. Superparamagnetic iron oxide polyacrylic acid coated gamma-Fe2O3 nanoparticles do not affect kidney function but cause acute effect on the cardiovascular function in healthy mice. Toxicol. Appl. Pharmacol. 2013, 266, 276-288.

(14) Rice, W. L.; Van Hoek, A. N.; Paunescu, T. G.; Huynh, C.; Goetze, B.; Singh, B.; Scipioni, L.; Stern, L. A.; Brown, D. High Resolution Helium Ion Scanning Microscopy of the Rat Kidney. PLoS One 2013, 8, No. e57051.

(15) Ferrari, R.; Yu, Y. C.; Morbidelli, M.; Hutchinson, R. A.; Moscatelli, D. epsilon-Caprolactone-Based Macromonomers Suitable for Biodegradable Nanoparticles Synthesis through Free Radical Polymerization. Macromolecules 2011, 44, 9205-9212.

(16) Ferrari, R.; Rooney, T. R.; Lupi, M.; Ubezio, P.; Hutchinson, R. A.; Moscatelli, D. A Methyl Methacrylate-HEMA-CLn Copolymerization Investigation: From Kinetics to Bioapplications. Macromol. Biosci. 2013, 13, 1347-1357.

(17) Ferrari, R.; Colombo, C.; Casali, C.; Lupi, M.; Ubezio, P.; Falcetta, F.; D'Incalci, M.; Morbidelli, M.; Moscatelli, D. Synthesis of surfactant free PCL-PEG brushed nanoparticles with tunable degradation kinetics. Int. J. Pharm. 2013, 453, 551-559.

(18) Rastaldi, M. P.; Li, M. Method for the Three-Dimensional CoCulture of Podocytes and Endothelial Cells and Relative in Vitro CoCulture System. EP2513295, Aug 10, 2016.

(19) Li, M.; Corbelli, A.; Watanabe, S.; Armelloni, S.; Ikehata, M.; Parazzi, V.; Pignatari, C.; Giardino, L.; Mattinzoli, D.; Lazzari, L.; Puliti, A.; Cellesi, F.; Zennaro, C.; Messa, P.; Rastaldi, M. P. Threedimensional podocyte-endothelial cell co-cultures: Assembly, validation, and application to drug testing and intercellular signaling studies. Eur. J. Pharm. Sci. 2016, 86, 1-12.

(20) Papa, S.; Rossi, F.; Ferrari, R.; Mariani, A.; De Paola, M.; Caron, I.; Fiordaliso, F.; Bisighini, C.; Sammali, E.; Colombo, C.; Gobbi, M.; Canovi, M.; Lucchetti, J.; Peviani, M.; Morbidelli, M.; Forloni, G.; Perale, G.; Moscatelli, D.; Veglianese, P. Selective Nanovector Mediated Treatment of Activated Proinflammatory Microglia/Macrophages in Spinal Cord Injury. ACS Nano 2013, 7, 9881-9895.

(21) Colombo, C.; Dragoni, L.; Gatti, S.; Pesce, R. M.; Rooney, T. R.; Mavroudakis, E.; Ferrari, R; Moscatelli, D. Tunable Degradation Behavior of PEGylated Polyester-Based Nanoparticles Obtained Through Emulsion Free Radical Polymerization. Ind. Eng. Chem. Res. 2014, 53, 9128-9135.

(22) Lupi, M.; Colombo, C.; Frapolli, R.; Ferrari, R.; Sitia, L.; Dragoni, L.; Bello, E.; Licandro, S. A.; Falcetta, F.; Ubezio, P.; Bigini, P.; Salmona, M.; D’Incalci, M.; Morbidelli, M.; Moscatelli, D. A biodistribution study of PEGylated PCL-based nanoparticles in C57BL/6 mice bearing B16/F10 melanoma. Nanotechnology 2014, 25, No. 335706.

(23) Papa, S.; Ferrari, R.; De Paola, M.; Rossi, F.; Mariani, A.; Caron, I.; Sammali, E.; Peviani, M.; Dell'Oro, V.; Colombo, C.; Morbidelli, M.; Forloni, G.; Perale, G.; Moscatelli, D.; Veglianese, P. Polymeric nanoparticle system to target activated microglia/macrophages in spinal cord injury. J. Controlled Release 2014, 174, 15-26.

(24) Papa, S.; Caron, I.; Erba, E.; Panini, N.; De Paola, M.; Mariani, A.; Colombo, C.; Ferrari, R.; Pozzer, D.; Zanier, E. R.; Pischiutta, F.; Lucchetti, J.; Bassi, A.; Valentini, G.; Simonutti, G.; Rossi, F.; Moscatelli, D.; Forloni, G.; Veglianese, P. Early modulation of proinflammatory microglia by minocycline loaded nanoparticles confers long lasting protection after spinal cord injury. Biomaterials 2016, 75, $13-24$.

(25) Sajjadi, S.; Yianneskis, M. Semibatch emulsion polymerization of methyl methacrylate with a neat monomer feed. Polym. React. Eng. 2003, 11, 715-736.

(26) Egen, M.; Zentel, R. Surfactant-free emulsion polymerization of various methacrylates: Towards monodisperse colloids for polymer opals. Macromol. Chem. Phys. 2004, 205, 1479-1488. 
(27) Bhattacharjee, S.; de Haan, L.; Evers, N.; Jiang, X.; Marcelis, A.; Zuilhof, H.; Rietjens, I.; Alink, G. Role of surface charge and oxidative stress in cytotoxicity of organic monolayer-coated silicon nanoparticles towards macrophage NR8383 cells. Part. Fibre Toxicol. 2010, 7, 25.

(28) Fröhlich, E. The role of surface charge in cellular uptake and cytotoxicity of medical nanoparticles. Int. J. Nanomed. 2012, 7, 55775591.

(29) Teixeira, V. D. C.; Blattner, S. M.; Li, M.; Anders, H. J.; Cohen, C. D.; Edenhofer, I.; Calvaresi, N.; Merkle, M.; Rastaldi, M. P.; Kretzler, M. Functional consequences of integrin-linked kinase activation in podocyte damage. Kidney Int. 2005, 67, 514-523.

(30) Schiffer, M.; Teng, B.; Gu, C.; Shchedrina, V. A.; Kasaikina, M.; Pham, V. A.; Hanke, N.; Rong, S.; Gueler, F.; Schroder, P.; Tossidou, I.; Park, J.-K.; Staggs, L.; Haller, H.; Erschow, S.; Hilfiker-Kleiner, D.; Wei, C.; Chen, C.; Tardi, N.; Hakroush, S.; Selig, M. K.; Vasilyev, A.; Merscher, S.; Reiser, J.; Sever, S. Pharmacological targeting of actindependent dynamin oligomerization ameliorates chronic kidney disease in diverse animal models. Nat. Med. 2015, 21, 601-609.

(31) Welsh, G. I.; Saleem, M. A. The podocyte cytoskeleton-key to a functioning glomerulus in health and disease. Nat. Rev. Nephrol. 2011, $8,14-21$.

(32) Zaki, N. M.; Tirelli, N. Gateways for the intracellular access of nanocarriers: a review of receptor-mediated endocytosis mechanisms and of strategies in receptor targeting. Expert Opin. Drug Delivery 2010, 7, 895-913.

(33) Pelkmans, L.; Helenius, A. Endocytosis Via Caveolae. Traffic 2002, 3, 311-320.

(34) Rejman, J.; Oberle, V.; Zuhorn, I. S.; Hoekstra, D. Sizedependent internalization of particles via the pathways of clathrin- and caveolae-mediated endocytosis. Biochem. J. 2004, 377, 159-169.

(35) Sahay, G.; Alakhova, D. Y.; Kabanov, A. V. Endocytosis of Nanomedicines. J. Controlled Release 2010, 145, 182-195.

(36) van Weert, A. W.; Dunn, K. W.; Gueze, H. J.; Maxfield, F. R.; Stoorvogel, W. Transport from late endosomes to lysosomes, but not sorting of integral membrane proteins in endosomes, depends on the vacuolar proton pump. J. Cell Biol. 1995, 130, 821-834.

(37) Verma, A.; Stellacci, F. Effect of Surface Properties on Nanoparticle-Cell Interactions. Small 2010, 6, 12-21.

(38) Ransom, R. F.; Lam, N. G.; Hallett, M. A.; Atkinson, S. J.; Smoyer, W. E. Glucocorticoids protect and enhance recovery of cultured murine podocytes via actin filament stabilization. Kidney Int. 2005, 68, 2473-2483.

(39) Xing, C. Y.; Saleem, M. A.; Coward, R. J.; Ni, L.; Witherden, I. R.; Mathieson, P. W. Direct effects of dexamethasone on human podocytes. Kidney Int. 2006, 70, 1038-1045.

(40) Krishnan, V.; Xu, X.; Barwe, S. P.; Yang, X.; Czymmek, K.; Waldman, S. A.; Mason, R. W.; Jia, X.; Rajasekaran, A. K. Dexamethasone-Loaded Block Copolymer Nanoparticles Induce Leukemia Cell Death and Enhance Therapeutic Efficacy: A Novel Application in Pediatric Nanomedicine. Mol. Pharmaceutics 2013, 10, 2199-2210.

(41) Ferrari, R.; Talamini, L.; Violatto, M. B.; Giangregorio, P.; Sponchioni, M.; Morbidelli, M.; Salmona, M.; Bigini, P.; Moscatelli, D. Biocompatible Polymer Nanoformulation To Improve the Release and Safety of a Drug Mimic Molecule Detectable via ICP-MS. Mol. Pharmaceutics 2017, 14, 124-134.

(42) Robson, J. S.; Mitchell, G. A. G.; Le Vay, D. Renal System. Human Excretion. In Encyclopedia Britannica, 2016. https://www. britannica.com/science/human-renal-system/Human-excretion.

(43) Blouch, K.; Deen, W. M.; Fauvel, J. P.; Bialek, J.; Derby, G.; Myers, B. D. Molecular configuration and glomerular size selectivity in healthy and nephrotic humans. Am. J. Physiol. 1997, 273, F430-F437.

(44) Guess, A.; Agrawal, S.; Wei, C.-C.; Ransom, R. F.; Benndorf, R.; Smoyer, W. E. Dose- and time-dependent glucocorticoid receptor signaling in podocytes. Am. J. Physiol.: Renal Physiol. 2010, 299, F845F853. 